\title{
Nitric oxide and L-type calcium channel influences the changes in arterial blood pressure and heart rate induced by central angiotesin
} II

\author{
Wilson A Saad*1,2,3,5, Ismael FMS Guarda ${ }^{4}$, Luiz AA Camargo ${ }^{3,5}$ and \\ Talmir AFB Santos ${ }^{1}$
}

\begin{abstract}
Address: ${ }^{1}$ Basic Institute of Biosciences-University of Taubaté, Taubaté, Brazil, ${ }^{2}$ Department of Exact and Natural Science Araraquara University Center, Araraquara, Brazil, ${ }^{3}$ Department of Physiology and Pathology School of Dentistry, Paulista State University, Araraquara, Brasil,

${ }^{4}$ Department of Anesthesiology Clinic Hospital State of São Paulo ,São Paulo, Brazil and ${ }^{5}$ Department of Physiology, Federal University of São Carlos, Brazil

Email: Wilson A Saad* - saad@foar.unesp.br; Ismael FMS Guarda - ismael@uol.com.br; Luiz AA Camargo - camargo@foar.unesp.br; Talmir AFB Santos - santos@unitau.com.br

* Corresponding author
\end{abstract}

Published: 24 May 2008

Behavioral and Brain Functions 2008, 4:22 doi:10.1 186/I744-908I-4-22
Received: 22 january 2008

Accepted: 24 May 2008

This article is available from: http://www.behavioralandbrainfunctions.com/content/4/I/22

(c) 2008 Saad et al; licensee BioMed Central Ltd.

This is an Open Access article distributed under the terms of the Creative Commons Attribution License (http://creativecommons.org/licenses/by/2.0), which permits unrestricted use, distribution, and reproduction in any medium, provided the original work is properly cited.

\begin{abstract}
We study the voltage dependent calcium channels and nitric oxide involvement in angiotensin IIinduced pressor effect. The antipressor action of L-Type calcium channel antagonist, nifedipine, has been studied when it was injected into the third ventricle prior to angiotensin II. The influence of nitric oxide on nifedipine antipressor action has also been studied by utilizing $\mathrm{NW}^{\mathrm{W}}$-nitro-L-arginine methyl ester (LNAME) $(40 \mu \mathrm{g} / 0.2 \mu \mathrm{l})$ a nitric oxide synthase inhibitor and L-arginine $(20 \mu \mathrm{g} / 0.2 \mu \mathrm{l})$, a nitric oxide donor agent. Adult male Holtzman rats weighting 200-250 g, with cannulae implanted into the third ventricle were injected with angiotensin II. Angiotensin II produced an elevation in mean arterial pressure and a decreased in heart rate. Such effects were potentiated by the prior injection of LNAME. L-arginine and nifedipine blocked the effects of angiotensin II. These data showed the involvement of L-Type calcium channel and a free radical gas nitric oxide in the central control of angiotensin II-induced pressor effect. This suggested that L-Type calcium channel of the circunventricular structures of central nervous system participated in both short and long term neuronal actions of ANG II with the influence of nitrergic system.
\end{abstract}

\section{Background}

Nitric oxide plays an important role in the hydromineral and cardiovascular regulation and influence several central angiotensin physiological parameters $[1,2]$. LNAME increases blood pressure which is at least in part salt sensitive [3]. A major factor that detemined a neuronal calcium-dependent signal is the opening of permeability pathways for calcium in the cell membrane [4]. However, the interaction between nifedipine (L-Type calcium chan- nel blocked agent) and nitrergic system of the circumventricular third ventricle structures of the central nervous system on the angiotensin II cardiovascular regulation has not been demonstrated.

The subfornical organ is an important circumventricular structure of the central nervous system that participated in the regulation of body fluid homeostasis [5-7]. LNAME significantly increased the discharge of neurons of the 
subfornical organ showing the importance of nitric oxide in the electrical activity of this structure [8]. FK 409 (a nitric oxide donor agent) injected into median preoptic nucleus of conscious rats decreased mean arterial pressure [9].

Treatment of neonatal rats with monosodium glutamate induced a substantial reduction in the volume of the subfornical organ and in the number of its nitrergic cells with regards to control animals [10]. These findings suggested that the subfornical organ could be implicated in some physiological functions such as salivary secretion and cardiovascular alterations observed in monosodium glutamate-treated rats.

The objective of this study was to determined the role of voltage-sensitive calcium channels in angiotensin IIinduced pressor response when it was injected into the third ventricle of conscious rats. We also studied the influence of a nitric oxide on the nifedipine effect.

\section{Methods}

The Medical Ethics Committee of the Universidade Estadual Paulista UNESP approved all protocols in this study.

Male Holtzman rats weighing 250-300 g were anesthetized with ketamine ( $80 \mathrm{mg} / \mathrm{Kg}$ of body weight) plus xylazine $(7 \mathrm{mg} / \mathrm{Kg}$ of body weight). A stainless steel cannula with 10 and $12-\mathrm{mm}$ long and $0.7-\mathrm{mm}$ OD was implanted into the $3^{\text {rd }} \mathrm{V}$ according to the coordinates of Paxinos and Watson atlas rat brain [11].

After the animals recovery from brain surgery (5 days) PE10 polyethylene tubing connected to PE-50 tubing was inserted into the abdominal aorta through the femoral artery. Direct mean arterial pressure and heart rate was record in unaesthetized and unrestrained rats. The animals were removed from their home cages and placed in test cages, without access to food or water. The previously implanted catheter was connected to a Statham (P23 Db) pressure transducer (Statham-Gould, Valley View, OH) coupled to a multi channel recorded (PowerLab Multirecord). This program permits the acquisition of cardiovascular data by computer. In these experiments the rats were chosen at random. Each animal was used no more than tree times.

The drugs were injected into the third ventricle by using a Hamilton micro syringe $(5 \mu \mathrm{l})$ connected by a PE-10 polyethylene tubing $(25 \mathrm{~cm})$ to a needle $(0.3 \mathrm{~mm} \mathrm{o}$. d.), which was introduced into the brain through the cannula previously fixed to the animals' head.

Mean arterial pressure and heart rate were record in conscious rats in a test cage, without access to food or water.
The results are reported as mean \pm S.E.M. The Analysis of variance and Newman-Keuls post-hoc test were used to determine the significance. The values were considered statistically significant with $5 \%$ level $(p<0.05)$.

\section{Results}

At the end of the experiments, the rats were anesthetized with ether and perfused with saline and buffered formalin. The brains were removed, fixed in $10 \%$ formalin, frozen to $-25^{\circ} \mathrm{C}$ and cut into $20-30 \mu \mathrm{m}$ coronal sections. Only animals in which the injection was placed into the third ventricle were used in this study (figure 1).

\section{Effects of nifedipine and L-arginine on the mean arterial pressure and heart rate induced by the injection of angiotensin II into the third ventricle Figure 2, 3}

Microinjections of angiotensin II into the third ventricle induced increase in means arterial pressure compared to control $(\Delta 18 \pm 2$ vs. control $\Delta 4 \pm 1 \mathrm{mmHg} \mathrm{p}<0.05)$ and decreased heart rate compared to control $\Delta-70 \pm 16$ vs. 21 $\pm 9 \mathrm{bpm} \mathrm{p}<0.05$ ). The microinjection of saline+nifedipine into the third ventricle caused no change in the mean arterial pressure $(\Delta 3.5 \pm 1 \mathrm{mmHg})$ and heart rate $(\Delta 20 \pm 9 \mathrm{bpm})$. Nifedipine $50 \mu \mathrm{g}$ injected into the third ventricle followed by angiotensin II decreased the pressor effect $(\Delta 11 \pm 1 \mathrm{mmHg} \mathrm{p}<0.01)$ with a decreased in heart rate $\Delta-10 \pm 2 \mathrm{bpm} \mathrm{p}<0.01)$. Nifedipine $100 \mu \mathrm{g}$ injected into the third ventricle followed by angiotensin II blocked angiotensin II-pressor effect $(5 \pm 1 \mathrm{mmHg} \mathrm{p}<0.01)$ and no changes in heart rate was observed $(\Delta 23 \pm 9 \mathrm{bpm})$. The injection of L-arginine also blocked the pressor effect of angiotensin II $(\Delta 4 \pm 1 \mathrm{mmHg} \mathrm{p}<0.01)$ no alterations in heart rate was observed $(\Delta 19 \pm 8 \mathrm{bpm})$. No alterations in mean arterial pressure and in heart rat was observed when $\mathrm{L}$-arginine was injected alone into the third ventricle ( $\mathrm{F}$ $(6,64)=63.4, \mathrm{p}<0.01)$ and $(\mathrm{F}(6,64)=63.4, \mathrm{p}<0.01)$ respectively.

\section{Effects of nifedipine and LNAME on the mean arterial pressure and heart rate induced by the injection of angiotensin II into the third ventricle Figure 4, 5}

Angiotensin II injected into the third ventricle increased mean arterial pressure and decreased heart rate. Nifedipine injected prior to angiotensin II decreased mean arterial pressure without changes in heart rate $(\mathrm{F}(4,38)=81.3$ $\mathrm{P}<0.01)$ and $\mathrm{F}(4,38)=78.3 \mathrm{P}<0.01$ respectively. The increased of mean arterial pressure induced by angiotensin II $(\Delta 17 \pm 1 \mathrm{mmHg})$ was potentiated by L-NAME $(25 \pm 2 \mathrm{mmHg} \mathrm{p}<0.01)$ with decreased in heart rate $(\Delta$ $60 \pm 6$ vs. $-80 \pm 10 \mathrm{bpm} \mathrm{p}<0.05)$. Rats injected with nifedipine $100 \mu \mathrm{g}$ prior to L-NAME followed by angiotensin II decreased the mean arterial presure $(7 \pm 2 \mathrm{mmHg} \mathrm{p}<$ $0.01)$ no alterations in heart rate was ovserved $(20 \pm 1$ bpm) $(\mathrm{F}(4,38)=81.3 \mathrm{P}<0.01)$ and $\mathrm{F}(4,38)=78.3 \mathrm{P}<$ 0.01 respectively. 


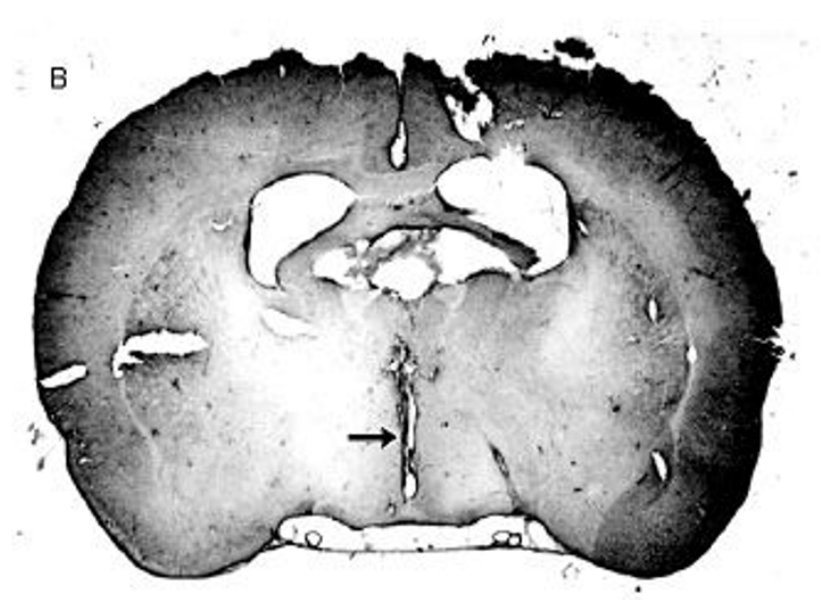

Figure I

Photomicrograph of the brain showing the place reached by the cannula into the $3^{\text {rd }} \mathrm{V}$ (arrow).

\section{Discussion}

In these experiments microinjections of angiotensin II into the third ventricle increased mean arterial pressure and decreased heart rate. which were blocked by nifedipine and potentiated by L-NAME. The microinjection of L-arginine into third ventricle decreased the pressor effect of angiotensin II no alterations in heart rate was opvserved. The injection of nifedipine combined with LNAME, which were injected prior to angiotensin II into the third ventricle, blocked the potentiation effect of LNAME. It has been demonstrated that injection of LNAME into the median proptic area increased the mean arterial pressure [12].

The treatment with L-NAME increased arterial blood pressure, which is at least in part salt sensitive. The action of LNAME also may be due to a local vasoconstriction. Furthermore, the salt-sensitive component appears to be angiotensin II-dependent, as it was associated with increase of plasma angiotensin II levels and could be reversed by the treatment with angiotensin II receptor antagonist [3].

These data, suggest that structures surrounding cerebral ventricles may release angiotensin II which acts as a neurotransmitter resulted in postsynaptic effects, which in turn influenced blood pressure and heart rate control. Angiotensinergic neural pathways and calcium channels are important in neural function and may have important homeostatic roles, particularly related to cardiovascular function by involved nitric oxide. It has been demonstrated that niric oxide antagonized the vasoconstrictive and pro-atherosclerotic effects of angiotensin II whereas angiotensin II decreased nitric oxide bioavailability by promoting oxidative stress.

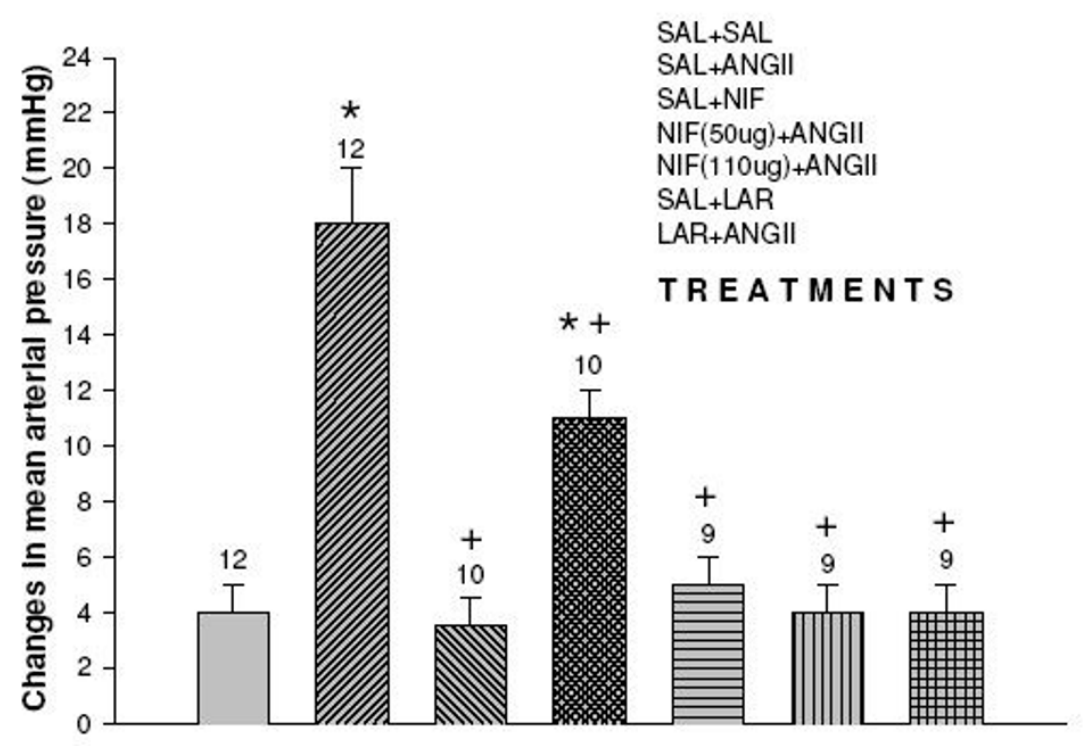

Figure 2

Effect of nifedipine and L-arginine on mean arterial pressure induced by the injection of angiotensin II into the third ventricle. Number of animals at the top of each column. Data are means \pm S.E.M. ${ }^{*} p<0.05$ vs.saline+saline, ${ }^{+} p<0.05$ vs. saline+angiotensin II (Neuman-Keuls post-hoc test). 


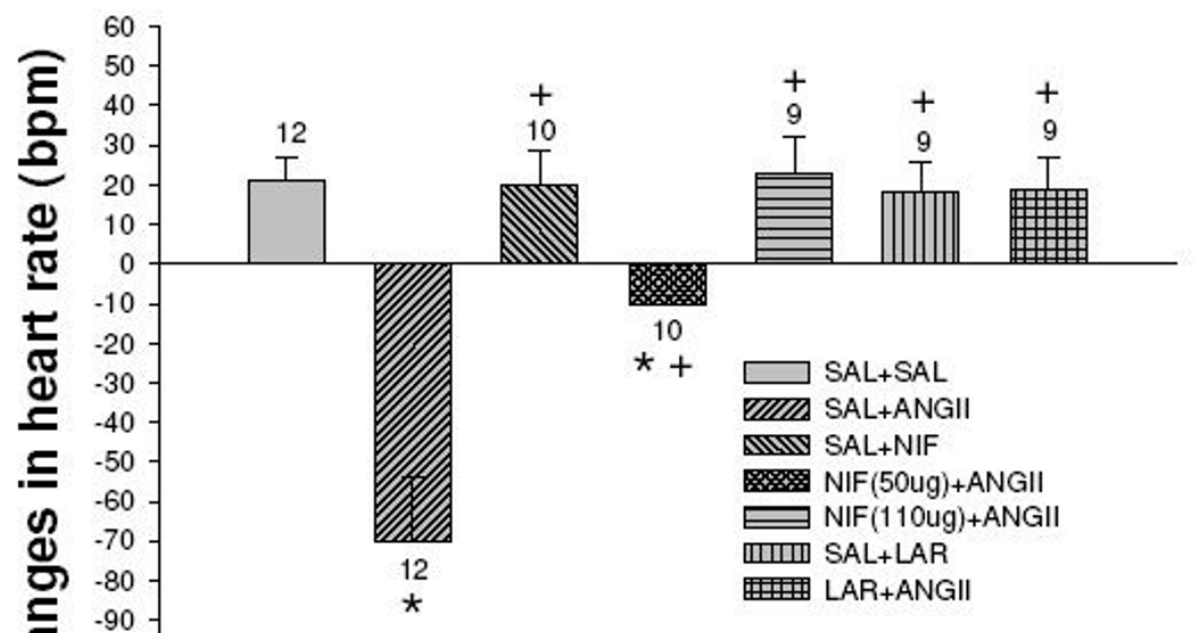

TREAT MEN TS

Figure 3

Effect of nifedipine and L-arginine on heart rate induced by the injection of angiotensin II into the third ventricle. Number of animals at the top of each column. Data are means \pm S.E.M. ${ }^{*} p<0.05$ vs.saline + saline, ${ }^{+} p<0.05$ vs. saline+angiotensin II (Neuman-Keuls post-hoc test).

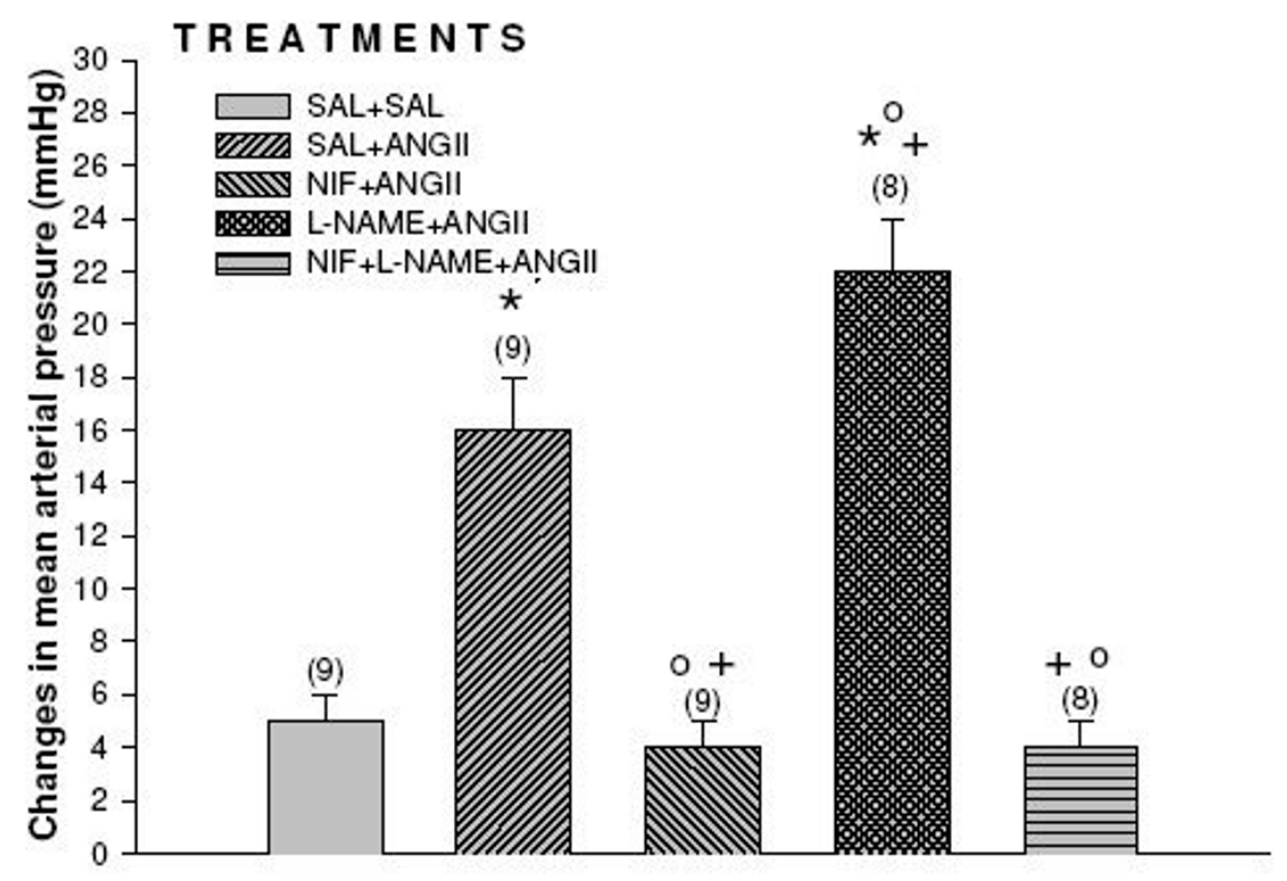

\section{Figure 4}

Effects of nifedipine and LNAME on the mean arterial pressure induced by the injection of angiotensin II into the third ventricle. Number of animals at the top of each column. Data are means \pm S.E.M. $* P<0.05$ vs. saline + saline, ${ }^{+} P<0.05$ vs. saline+angiotensin II and OP < 0.05 vs. LNAME+angiotensin II (Neuman-Keuls post-hoc test). 


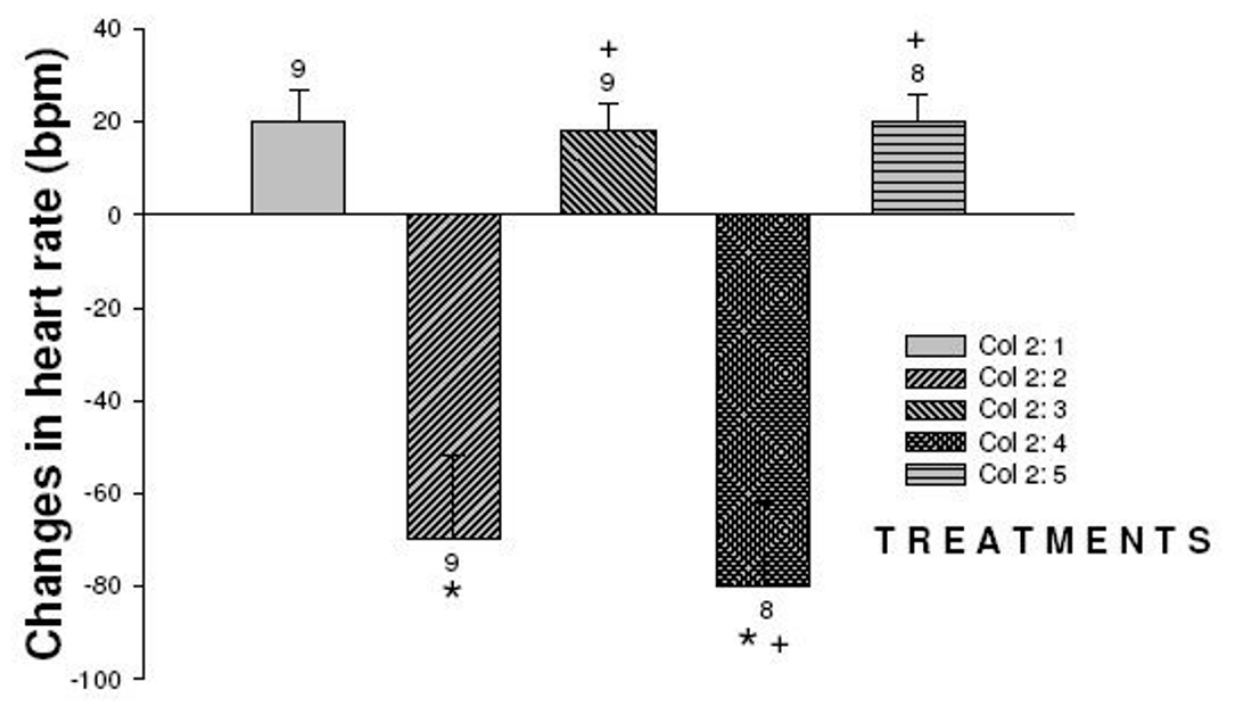

\section{Figure 5}

Effects of nifedipine and LNAME on heart rate induced by the injection of angiotensin II into the third ventricle. Number of animals at the top of each column. Data are means \pm S.E.M. $* P<0.05$ vs. saline+saline, ${ }^{+} P<0.05$ vs. saline + angiotensin II and OP $<$ 0.05 vs. LNAME+angiotensin II (Neuman-Keuls post-hoc test).

By the results of the present study we can suggested that nifedipine may have interfered with calcium influx in the presynaptic terminals, where L-type calcium channels play important roles in modulated presynaptic neurotransmitter release. It may also have altered $\mathrm{Ca}^{2+}$-dependent signal events in postsynaptic neurons since previous studies demonstrated the permissive effects of voltage sensitive calcium channels on monosodium glutamatetreated rats receptor-mediated calcium influx. In most neurons of the central nervous system, there are at least two major classes of calcium channel: voltage sensitive and receptor-operated calcium channels. Ours results are strongly supported by the results of others that demonstrated the hypertensive effect of angiotensin II significantly enhanced by prior microinjection of LNAME into paraventricular nucleus this showed that the effect of angiotensin II in arterial blood pressure interact with nitric oxide [13-16].

\section{Conclusion}

The main find of these experiments is that nifedipine with or without L-NAME blocked the effect of angiotensin II on arterial blood pressure and heart rate. We can explained that the pressor effect of angiotensin II injected into third ventricle acted into the circumventricular structures and utilized L-Type calcium channel to exerted it effects. The nitric oxide also participated in angiotensin II effect. The influence of L-Type calcium channel and nitric oxide utilizing cGMP pathways on angiotensin II pressor effect explained these results. Finally we demonstrated that angiotensin II utilized the calcium channel and nitric oxide to exerced the central regulation of arterial blood and heart rate. These results provide support to future studies that involved specific circumventricular structures.

\section{List of abreviations}

SAL: saline; ANGII: angiotensin II; LAR: L-arginine; NIF: nifedipine; L-NAME: L-NAME

\section{Competing interests}

The authors declare that they have no competing interests.

\section{Authors' contributions}

WAS made substantial contributions to conception and design, or acquisition of data

IFMSG analyzed the data and have been involved in drafting the manuscript

LAAC revised and made critically for important intellectual content

TAFBS made the figures and performed the statistical analysis

\section{Acknowledgements}

The authors greatly appreciate the assistance of Luciana Rizuti Saad for preparation of the manuscript, and Ana V. Oliveira and Fernando L. Capelli for animal care. Research supported by CNPq (520408/96.9), FAPESP (99/ 
06582-2 and 02/03806-I), FUNDUNESP (0I/06756-3), PRONEX and FUNADESP-UNIARA.

\section{References}

I. Saad WA, Guarda IFMS, Guarda RS, Camargo LAA, Santos TAFB, Saad WA, Simões S: Role of nitric oxide and beta receptors of the central nervous system on the salivary flow induced by pilocarpine injection into the lateral ventricle. Pharmacol Biochem Behav 2002, 72(1-2):229-235.

2. WA Saad WA, LAA Camargo LAA, IFSM Guarda IFMS, TAFB Santos TAFB, Guarda RS, Saad WA, Simões S, Antunes Rodrigues J: Role of nitric oxide of the median preoptic nucleus (MnPO) in the alterations of salivary flow, arterial pressure and heart rate induced by injection of pilocarpine into the MnPO and intrperitoneally. Braz J Med Biol Res 2003, 36:897-905.

3. Hodge G, Ye VZ, Duggan KA: Salt-sensitive hypertension resulting from nitric oxide synthase inhibition is associated with loss of regulation of angiotensin II in the rat. Exp Physiol 2002, 87: $1-8$.

4. Tsien RW, Lipscombe V, Madison DV, Bley KR, Fox AP: Multiple types of neuronal calcium channels and their selective modulation. Trends Neurosci 1988, I I:431-438.

5. Mangiapane ML, Simpson JB: Subfornical organ: forebrain site of pressor and dipsogenic action of angiotensin II. Am J Physiol 1980, 239:R382-R389.

6. Thunhorst RL, Erlich KJ, Simpson JB: Subfornical organ participates in salt appetite. Behav Neurosci 1990, 104:637-642.

7. Yang H, Lu D, Raizafa MK: Lack of cross talk between $\alpha_{1}$ - adrenergic and angiotensin type I receptors in neurons of spontaneous hypertensive rats. Hypertension 1996, 27:1277-I283.

8. Li M, Wang QS, Chen Y, Wang ZM, Lui Z, Guo SM: Resveratrol inhibits the electrical activity of subfornical organ neurons in rat. Sheng $L i$ Xue Bao 2005, 57(4):523-528.

9. Saad WA, Gutierrez LI, Guarda IFSM, Camargo LAA, Santos TAFB, Saad WA, Simões Silvio, Guarda RS: Lateral hypothalamus lesions influences water and salt intake, and sodium and urine excretion, arterial blood pressure induced by L-NAME and FK 409 injections into median preoptic nucleus in conscious rats. Life Sci 2004, 75:685-697.

10. Pesini P, Rois JL, Menendez L, Vidal S: The neonatal treatment of rats with monosodium glutamate induces morphological changes in the subfornical organ. Anat Histol Embryol 2004, 33:273-277.

II. Paxinos G, Watson C: The rat brain in stereotaxic coordinates. New York: Academic Press; 1986.

12. Saad WA, Gutierrez LI, Guarda IFMS, Camargo LAA, Santos TAFB, Saad WA, Simões S, Guarda RS: Lateral hypothalamus lesions influences water and salt intake, and sodium and urine excretion, arterial blood pressure induced by L-NAME and FK 409 injections into median preoptic nucleus in conscious rats. Life Sci 2004, 75:685-697.

13. Saad WA, Camargo LAA, Rodrigues JA, Saad WA, Guarda IFMS, Guarda RS: Interaction between arginine vasopressin and angiotensin II receptors in the central Nervous system in the regulation of sodium balance. Regul Pept 2005, I 32(I-3):53-58.

14. Saad WA, Camargo LAA, Guarda IFMS, Saad WA: I-type calcium channel mediate water intake induced by angiotensin injection into median preoptic nucleus. Pharmacol Biochem Behav 2006, 83(4):598-602.

15. Saad WA, Camargo LAA, Guarda IFMS, Saad WA: Functional relationship between subfornical organ cholinergic stimulation and nitrergic activation influencing cardiovascular and body fluid homeostasis. Regul Pept 2007, I43( I-3):28-33.

16. Li YF, Wang W, Mayhan WG, Patel KP: Angiotensin-mediated increase in renal sympathetic nerve discharge within the PVN: role of nitric oxide. Am J Physiol Regul Integr Comp Physiol 2006, 290(4):RI035-RI043. http.//www.behavioralandbrainfunctions.com/content/4/1/22 